\title{
A coevolução das capacidades tecnológicas entre empresas multinacionais (MNE) e Pequenas e Médias Empresas (PME) de Tecnologia da Informação e Comunicação (TIC) em redes de tecnologia e inovação
}

\author{
The coevolution of technological capabilities \\ among Mutinational Enterprises (MNE'S) and Small \\ and Medium Enterprises (SME'S) of Information \\ Technology and Comunications (ITC)in innovation \\ and technology networks
}

\section{Antônio Carlos Farias Coelho Samuel Façanha Câmara Alexander Brasil}

\section{Resumo}

O estudo examina a coevolução das capacidades tecnológicas entre empresas multinacionais ( $\mathrm{MNC}$ ) e pequenas e médias empresas (PME) de tecnologia da informação e comunicação (TIC) em redes de tecnologia e inovação, por meio de estudo de caso comparativo longitudinal de duas subsidiárias de MNC do setor de Tecnologia da Informação (TI) e uma PME do mesmo setor, no período de 2004 a 2012. O estudo demonstrou a ocorrência de coevolução em ambos os projetos analisados, contudo, foi constatada forte assimetria entre as empresas em termos da natureza e da velocidade na coevolução das capacidades tecnológicas entre MNC e PME, possivelmente fruto do maior envolvimento das MNC nas fases iniciais dos projetos. Isso demonstra que as PME, de maneira geral, para obterem êxito em seu processo de construção e desenvolvimento de capacidades tecnológicas, devem

Mestre em Administração. Universidade Estadual do Ceará. Av. Silas Munguba, 1700, Campus do Itaperi, Fortaleza-CE. Brasil CEP: 60.714.903. Fone: 055.85.3101- 9940. E-mail: farias@ oktiva.com.br

2 Doutor em Economia. Universidade Estadual do Ceará. E-mail: samuel.camara@uece.br

3 Mestrando em Administração. Universidade Estadual do Ceará. E-mail: alexander_brasil@ yahoo.com.br 
trabalhar para reduzir esse gap, seja por meio da adoção de práticas positivas de gestão de projetos de inovação, seja pela melhoria na qualificação e autonomia da liderança dessas organizações.

Palavras-chave: Capacidades Tecnológicas. Inovação. Redes de Tecnologia. Coevolução.

\section{Abstract}

This paper examines the coevolution of technological capabilities among Multi National Companies (MNC's) and Small and Medium Enterprises (SME's) from the Information Technology and Communication (ITC) sector in innovation and technology networks using a longitudinal comparative case study from a couple of subsidiaries of MNC's and one SME from the IT sector, in the period of 2004 and 2012. The main findings were that the coevolution in both projects have occurred, but not without a strong asymmetry among them in terms of the speed and nature of the coevolution process of technological capabilities, what can be attributed to a major involvement of MNC's at the beginning of the projects. This demonstrates that if SME's, in general, wants to succeed in the building process and development of technological capabilities, they must work in the sense of filling this gap, either by the adoption of best practices in projects management or by the development of skills and autonomy of leadership from those firms.

Keywords: Technological capabilities, Innovation;Technology networks; Coevolution.

\section{Introdução}

Diversos trabalhos têm se preocupado em avaliar a atuação de subsidiárias de Multi National Companies (MNC) em países de economia emergente, especialmente a relação entre essas subsidiárias e as economias locais desses países (BIRKINSHAW; HOOD, 1998; CANTWELL; MUDAMBI, 2005; CHANG; MELLAHI; WILKINSON, 2009; FIGUEIREDO; BRITO, 2011; MEYER; MUDAMBI; NARULA, 2011). Entretanto, os diferentes níveis de envolvimento dessas subsidiárias com as empresas locais sofrem influências da estratégia e da cultura da matriz.

Birkinshaw e Hood (1998) já haviam identificado que a autonomia dada pela matriz às subsidiárias, associada ao dinamismo da economia 
local, é um fator-chave na determinação de suas relações locais. Essas relações, que envolvem diferentes atores, se estabelecem por meio de fornecedores, governo, instituições de apoio e, em diferentes dimensões, estão associadas a ações de compra e venda, logística, conhecimento e inovação - esta, objeto de interesse deste trabalho. Observou-se que os estudos com essas perspectivas tendem a apresentar dois direcionamentos: o primeiro diz respeito às $\mathrm{MNC}$ e os resultados de suas subsidiárias a partir de seus diferentes níveis de envolvimento (CANTWELL; MUDAMBI, 2005; FROST, 2001; HEDLUND, 1986; ANDERSSON; FORSGREN; HOLM, 2002; LIU; WU, 2011), assim como o estudo desse envolvimento em países emergentes (FIGUEIREDO, 2011; FIGUEIREDO; BRITO, 2011; KOKKO; KRAVTSOVA, 2008; MEYER; MUDAMBI; NARULA, 2011; VAALER, 2008). Já a segunda abordagem diz respeito ao envolvimento externo das PME e o impacto em sua capacidade inovativa, destacando-se os trabalhos de Gronum,Verreynne e Kastelle (2012), Lasagni (2012) e Liu e Chaminade (2010); e em uma abordagem mais evolucionária, o trabalho de Malerba e Orsenigo (1993).

No Brasil, o exemplo mais preeminente da importância desses relacionamentos vem do setor de Tecnologia da Informação e Comunicação (TIC). Desde a promulgação da Lei n 8248/91, também conhecida como Lei da Informática, as PME do setor vêm experienciando situações positivas, em que, juntamente com subsidiárias de MNC, universidades e institutos de pesquisa, projetos e parcerias surgem e geram frutos. Segundo Salles Filho et al. (2012), dados do IBGE dão conta de que as empresas que fazem uso da Lei da Informática inovaram duas vezes mais que outras empresas do setor, e 35\% delas desenvolveram inovações a partir de P\&D externo, contra $17 \%$ do restante da indústria.

Todavia, conquanto os estudos da evolução nas capacidades tecnológicas nas relações entre PME e subsidiárias de MNC do setor de TIC estejam contribuindo para o aprendizado e direcionamento inovativo do setor, pouco se sabe sobre a coevolução das capacidades tecnológicas que as empresas dessa relação vêm auferindo, sua magnitude e seus 
impactos sobre o ímpeto inovativo das empresas do arranjo. Com efeito, entender os mecanismos da coevolução nessas redes, na medida em que proporciona direcionamentos sobre práticas e políticas proativas de incentivo e participação dos atores na rede, contribui para a sua eficácia e, consequentemente, seu desenvolvimento. Assim, diante dessa lacuna e por sua relevância, este estudo procura lançar luz à temática objetivando responder ao seguinte questionamento: Qual o impacto da coevolução das capacidades tecnológicas de MNC e PME do setor de TIC que se relacionam em redes de tecnologia e de inovação?

O artigo se encontra estruturado em cinco seções incluindo esta introdução. A seção 2 analisa e descreve a formação do framework analítico proposto, seus construtos e pressupostos. Na seção 3, são discutidos os aspectos metodológicos da pesquisa, bem como o método de coleta e análise de dados. A seção 4 expõe a análise das evidências empíricas sobre a coevolução das capacidades tecnológicas entre as subsidiárias de MNC e as PME de TIC em redes de tecnologia e inovação. Por fim, a seção 5 apresenta as considerações finais acerca da temática e sugestões para pesquisas futuras.

\section{Frameworks analíticos}

Para Cantwell e Mudambi (2005), a evolução e o desenvolvimento de capacidades tecnológicas inovadoras em subsidiárias de MNC requer uma combinação entre iniciativa local e pré-disposição da matriz em suportar o esforço inovativo de sua subsidiária. O processo de inovação não é necessariamente encorajado pela matriz, então, a autonomia da subsidiária é fundamental ao processo, pois, como destacado por Boehe (2005), a autonomia das subsidiárias de MNC é fator crítico para a acumulação de capacidades tecnológicas inovadoras, assertiva corroborada por Ariffin e Figueiredo (2004), que destacam o importante papel das subsidiárias das MNC para a competitividade das matrizes.

Com o intuito de melhor entender essa evolução e o desenvolvimento de capacidades, diversos estudos foram empreendidos. 
Cantwell e Mudambi (2005) observaram que a relação de autorização e autonomia da subsidiária em relação à matriz, em condições favoráveis, permitia a criação de competências que impulsionavam a P\&D local em busca da inovação tecnológica radical, ao passo que, em condições desfavoráveis, a P\&D local tenderia a focar em inovações incrementais. Já Anderson, Forsgren e Holm (2002) auferiram que as relações com os atores individuais possibilitavam que as subsidiárias absorvessem novos conhecimentos a partir do ambiente, afetando positivamente seu desempenho no mercado local. Entretanto, Liu e Chaminade (2010) ponderam que redes de inovação tecnológica são mais adequadas à inovação de processo, podendo não ser efetivas para inovação de produto. Ainda nessa vertente, diversos trabalhos tentaram estudar a relação entre redes e desempenho, seja por meio da incorporação de tecnologias relacionais e estruturais (LIU; WU, 2011), seja por meio da análise da dinâmica do desempenho inovador das subsidiárias, sua imersão em sistemas de conhecimentos locais e estruturas políticas (FIGUEIREDO; BRITO, 2011), seja pelo estudo da inovação como variável mediadora do desempenho em redes (GRONUM; VERREYNNE; KASTELLE, 2012).

Assim, o framework proposto inova ao incorporar as dimensões anteriormente abordadas e ao propor o estudo coevolutivo das empresas, estrangeiras e locais, quando se envolvem em redes que primam pela evolução tecnológica comum, pela resolução de problemas e pelo aproveitamento de oportunidades. Neste caso, a coevolução se dará pelas influências de variáveis, como autonomia, participação em redes e mecanismos de aprendizagem, por meio da relação entre as subsidiárias e as PME's. O framework analítico proposto pode ser observado na Figura 1 e será detalhado mais adiante. 
Figura 1 - Framework Proposto - Envolvimento de Subsidiária de MNC`s e PME's

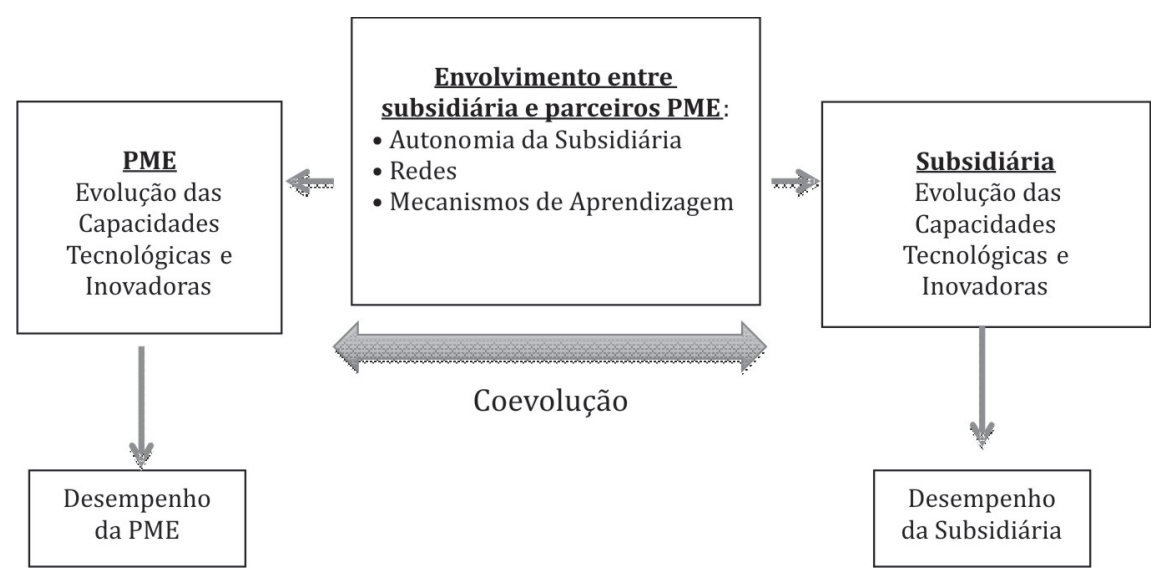

Fonte: Câmara (2012)

\subsection{Coevolução}

A coevolução objetiva descrever situações nas quais organizações e populações não só respondem à influência do meio, mas também o afetam de alguma forma (ALDRICH, 2005; BAUM; SINGH, 1994; LAMAS, 2005; NELSON, 1995). Segundo McKelvey (1997), a teoria coevolucionária sugere que a adaptação ocorre em dois níveis: macroevolução - que representa a adaptação da firma ao seu ambiente externo - e microevolução - que representa a adaptação interna dos processos, tarefas, rotinas e estruturas da firma. Já Lewin, Long e Carroll (1999) argumentam que a evolução de novas formas de organização é um resultado da coevolução do ambiente competitivo, intencionalidade da firma e o ambiente institucional da firma sob condições de incerteza ambiental estocástica ou caótica. Ou seja, a evolução de uma comunidade organizacional pode ser conceituada como a coevolução de suas partes constituintes (CARNEY; GEDAJLOVIC, 2000). 


\subsection{Envolvimento entre subsidiárias de MNC e parceiros PME}

O construto "envolvimento" considera que a subsidiária possui algum nível de autonomia em relação à empresa-mãe (MNC), logo, o papel das subsidiárias deixaria de estar restrito à função de adaptar a tecnologia da matriz às necessidades do mercado local (LI; FERREIRA; SERRA, 2009) e passaria a incluir importantes fontes de desenvolvimento tecnológico (GHOSHAL; BARTLETT, 1988; LI; FERREIRA; SERRA, 2009). E no caso das redes em estudo, a cooperação entre atores externos aumenta a habilidade de reorganizar a base de conhecimentos (LÜTZ, 1997) e, uma vez que o conhecimento organizacional não se constrói por si só, a socialização do conhecimento em rede fortalece ainda mais a aprendizagem organizacional, na medida em que características complementares são somadas e geram conhecimento capaz de conduzir ao acúmulo de capacidades tecnológicas que levam à inovação (POWELL; KOPUT; NONAKA; TAKEUCHI, 2008; RUAS; ANTONELLO; BOFF, 2005; SMITH-DOERR, 1996).

\subsection{Capacidades tecnológicas}

Para Lall (1992), capacidade tecnológica é o resultado dos investimentos feitos em resposta aos estímulos, internos e externos, e interações com outros agentes econômicos, privados ou públicos, locais ou estrangeiros. De outra forma, Bell e Pavitt (1995) a definem como a diferença substancial entre os conhecimentos necessários para realizar a mudança dos sistemas utilizados dos necessários para manter os existentes. Já para Kim (1999), a capacidade tecnológica refere-se à habilidade de fazer uso efetivo do conhecimento tecnológico, sendo este, para ele, o principal determinante da competitividade industrial. Outros autores contemporâneos como Garcia-Muiña e Navas-López (2007) e Von Zedtwitzet al. (2007) acrescentam ainda que as capacidades tecnológicas devem evoluir com o ambiente, gerando conhecimentos que ao mesmo tempo em que induzem a inovação, garantem às organizações a habilidade em responder as mudanças ambientais. 


\subsection{Desempenho inovativo}

De acordo com Figueiredo (2003), a performance inovativa das firmas pode ser mensurada, principalmente, pela incorporação de melhorias e ou de novos processos e produtos. Para Cassiolato e Lastres (2005), o desempenho inovativo depende de como empresas, organizações de ensino e pesquisa, instituições - inclusive as políticas - e os outros atores da rede interagem entre si e como afetam o desenvolvimento dos sistemas. Com efeito, para Stallivieri, Matos e Souza (2006), as relações de cooperação representam um importante elemento para o desempenho inovativo por potencializarem o aprendizado interativo e levar à geração e difusão de novos conhecimentos.

\section{Aspectos metodológicos}

Para operacionalização do estudo, foi utilizado o método de estudo multicaso, observando os preceitos de Alves-Mazzotti (2006), Godoy (1995), Miles e Huberman (1994) e Yin (2001). Foram analisadas duas empresas subsidiárias de MNC e uma PME, todas participantes de redes de tecnologia e inovação do setor de TIC. Foram utilizadas como fontes de dados para a análise do framework proposto entrevistas semiestruturadas com 10 funcionários-chave das empresas eleitas, selecionados por acessibilidade e pelo método bola de neve, análise documental interna e externa e, em certo ponto, observação participante. As características das empresas participantes no estudo estão dispostas no Quadro 1. No Quadro 2, são declarados os participantes do processo, bem como suas posições dentro da organização à qual pertencem. Os nomes das empresas foram modificados e os dos participantes, omitidos, para preservar a privacidade e garantir a participação efetiva do entrevistado. 
Quadro 1: Empresas selecionadas.

\begin{tabular}{|l|l|l|l|l|l|l|}
\hline & & S & & & \\
\hline Alfa & Taubaté-SP & 1971 & Grande & Estrangeira & $\begin{array}{l}\text { Produto } \\
\text { /serviço }\end{array}$ & Empresa do ramo de automação. \\
\hline Alfa1 & Curitiba-PR & 1896 & Grande & Estrangeira & $\begin{array}{l}\text { Produto } \\
\text { /serviço }\end{array}$ & $\begin{array}{l}\text { Empresa do ramo de med idores de } \\
\text { energia elétrica. }\end{array}$ \\
\hline Beta & Ceará & 2003 & Pequena & Nacional & Serviço & $\begin{array}{l}\text { Empresa que atua no planejamento, } \\
\text { articulação, negociação, gestão e } \\
\text { execução de projetos de TI. }\end{array}$ \\
\hline
\end{tabular}

Fonte: Figueiredo e Miranda (2009)

Quadro 2: Profissionais entrevistados e seu perfil acadêmico.

\begin{tabular}{|l|l|}
\hline Entrevistado & Perfil \\
\hline Diretor Subsidiária de MNC (Alfa) & Doutor em Sistemas de Informação \\
\hline Diretor Subsidiária de MNC (Alfa1) & Doutor em Processamento de Dados \\
\hline Diretor da PME (Beta) & Mestre em Ciência da Computação \\
\hline Gerente de Projetos da ICT & Mestre em Administração \\
\hline Coordenador Regional da MNC (Alfa) & Especialista e Engenharia da Computação \\
\hline Coordenador Regional da MNC (Alfa1) & Mestre em Ciência da Computação \\
\hline Coordenador Técnico da PME (Beta) & Especialista em Sistemas de Informação \\
\hline Analista de Sistemas da PME (Beta) & Graduado em Análise de Sistemas \\
\hline Analista de Sistemas da PME (Alfa) & Especialista em Ciência da Computação \\
\hline Analista de Sistemas da PME (Alfa1) & Especialista em Sistemas de Informação \\
\hline
\end{tabular}

Fonte: Empresas pesquisadas (2013)

O roteiro da entrevista foi adaptado para o contexto setorial específico, a partir de trabalhos que abordam temáticas sobre acumulação de capacidades tecnológicas em diferentes organizações, de diferentes setores industriais, inseridas em economias em desenvolvimento, como Andrade e Figueiredo (2008), na subsidiária da Motorola do setor de TIC; Fonseca e Figueiredo (2014), na Rioquima do setor químico; e Frohard (2009), que analisou comparativamente a MetsoPaper sulamericana e a Aracruz Celulose do setor celulose. As entrevistas foram realizadas no período de $1^{\circ}$ de março de 2013 a 26 de abril de 2013, na 
sede das empresas em estudo, período durante o qual também foram empreendidas as outras etapas de coleta, como análise de documentos e observação direta.

\section{Análises e discussão}

A partir das evidências empíricas apresentadas no Quadro 3, podese observar que a autonomia das subsidiárias de MNC, durante a fase de planejamento, esteve relacionada com o estabelecimento do escopo dos projetos analisados (objetivo, metodologia e entrega). Nesse sentido, percebe-se certa assimetria de autonomia na relação entre subsidiária e PME. No caso da PME, a sua autonomia na fase de planejamento se revelou por meio de sua influência na construção das exigências das competências e habilidades das pessoas selecionadas para a execução das atividades do projeto. Embora essa responsabilidade possa parecer pouca, revela a importância da PME nesse processo, uma vez que projetos de P\&D no segmento de TIC possuem nos recursos humanos seu ativo mais relevante.

Quadro 3: Autonomia das subsidiárias e uma PME em relação a uma MNC demandante de um projeto de P\&D e controladora das subsidiárias

\begin{tabular}{|c|c|c|c|c|}
\hline Embededness & \multicolumn{2}{|c|}{ Planejamento 2004} & $\begin{array}{l}\text { Execução } 2005 \text { - } \\
2012\end{array}$ & $\begin{array}{l}\text { Apropriação } \\
\text { resultados }\end{array}$ \\
\hline \multirow[b]{2}{*}{ Projeto 1} & $\begin{array}{l}\text { PME } \\
\text { Beta }\end{array}$ & $\begin{array}{l}\text { Influência na c onstrução } \\
\text { das exigências nas } \\
\text { competências e habilidades } \\
\text { das pessoas selecionadas. }\end{array}$ & $\begin{array}{l}\text { Gestão de pessoal } \\
\text { compartilhada com } \\
\text { a subsidiária da } \\
\text { MNC. }\end{array}$ & \\
\hline & $\begin{array}{l}\text { SMNC } \\
\text { Alfa }\end{array}$ & $\begin{array}{l}\text { Estabelecimento de escopo } \\
\text { (objetivos, metodologia e } \\
\text { entrega). }\end{array}$ & $\begin{array}{l}\text { Acompanhamento } \\
\text { dos resultados } \\
\text { parciais através de } \\
\text { reuniões periódicas } \\
\text { e apresentações de } \\
\text { relatórios. }\end{array}$ & $\begin{array}{l}\text { A decisão de registro de } \\
\text { software. }\end{array}$ \\
\hline \multirow[b]{2}{*}{ Projeto 2} & $\begin{array}{l}\text { PME } \\
\text { Beta }\end{array}$ & $\begin{array}{l}\text { Influência na construção } \\
\text { das exigências nas } \\
\text { competências e habilidades } \\
\text { das pessoas selecionadas. }\end{array}$ & $\begin{array}{l}\text { Gestão de pes soal } \\
\text { compartilhada com } \\
\text { a subsidiária da } \\
\text { MNC. }\end{array}$ & \\
\hline & $\begin{array}{l}\text { SMNC } \\
\text { Alfa1 }\end{array}$ & $\begin{array}{l}\text { Estabelecimento de escopo } \\
\text { (objetivos, metodologia e } \\
\text { entrega). }\end{array}$ & $\begin{array}{l}\text { Acompanhamento } \\
\text { dos resultados } \\
\text { parciais através de } \\
\text { reuniões periódicas } \\
\text { e apresentações de } \\
\text { relatórios. }\end{array}$ & \\
\hline
\end{tabular}

Fonte: Resultados da pesquisa (2013) 
Verificou-se que quase não existe autonomia por parte da subsidiária e da PME na fase de apropriação de resultados dos projetos de P\&D, o que se explica pelo fato de que essas decisões são tomadas no âmbito da matriz (MNC), assim como a distribuição e alocação destes ativos. É comum nestes casos que o projeto tenha uma forte aplicação na subsidiária envolvida, porém, a decisão de uso é da sede da empresa controladora. É possível que o conhecimento tácito gerado nos projetos seja apropriado de maneira informal pelos membros das equipes dos projetos, contudo, esta apropriação não se transfere de forma integral, tanto pela falta de mecanismos mais eficazes na condução destas transferências, como pelo não aproveitamento das equipes envolvidas nos quadros permanentes das subsidiárias e da PME.

\subsection{Redes}

Conforme apresentado no Quadro 4, durante a fase de planejamento, houve envolvimento entre a ICT que abriga o projeto, as subsidiárias de MNC e a PME na definição do escopo e orçamento do projeto, por meio de diversas reuniões realizadas no ambiente físico da ICT. Esta rede, de poucos atores institucionais, caracterizou-se por certa distância da empresa-mãe nas ações de planejamento dos projetos. Por outro lado, as decisões foram mais concentradas na subsidiária, representando o elo entre os outros participantes da rede (i.e.: PME e ICT). O ICT se relacionou de forma mais intensa com a subsidiária no planejamento dos projetos, visando principalmente o compartilhamento de recursos e a construção orçamentária. 
Quadro 4: Benefícios que recebem subsidiárias e PME por se envolverem em rede de tecnologia e inovação

\begin{tabular}{|c|c|c|c|c|}
\hline Projetos & \multicolumn{2}{|c|}{ Planejamento 2004} & Execução 2005-2012 & $\begin{array}{l}\text { Apropriação dos } \\
\text { resultados } \\
\text { 2011-2012 }\end{array}$ \\
\hline \multirow{2}{*}{ Projeto 1} & $\begin{array}{l}\text { PME } \\
\text { Beta }\end{array}$ & $\begin{array}{l}\text { Envolvimento com a ICT que } \\
\text { abriga o projeto e a subsidiária } \\
\text { da MNC na definição do } \\
\text { escopo e orçamento, mediante } \\
\text { sucessivas reuniões realizadas } \\
\text { no ambiente da ICT. }\end{array}$ & $\begin{array}{l}\text { Capacitação com o } \\
\text { pessoal da subsi diaria } \\
\text { na sede da subsidiária } \\
\text { e ou por meio de } \\
\text { outros si stemas de } \\
\text { comunicação (vídeo } \\
\text { conferência). }\end{array}$ & $\begin{array}{l}\text { Transferência de } \\
\text { conhecimento em } \\
\text { metodologias e } \\
\text { processos para a PME, } \\
\text { fruto da relação com a } \\
\text { ICT e da subsidiária. }\end{array}$ \\
\hline & $\begin{array}{l}\text { SMNC } \\
\text { Alfa }\end{array}$ & Idem ao da PME. & $\begin{array}{l}\text { Identificação de } \\
\text { competências em } \\
\text { pessoal técnico } \\
\text { distribuído em outra } \\
\text { região (onde se } \\
\text { localizam a ICT e a } \\
\text { PME) }\end{array}$ & $\begin{array}{l}\text { Por meio da rede foi } \\
\text { possível } \\
\text { desenvolvimento de } \\
\text { outros projetos. }\end{array}$ \\
\hline \multirow[t]{2}{*}{ Projeto 2} & $\begin{array}{l}\text { PME } \\
\text { Beta }\end{array}$ & $\begin{array}{l}\text { Envolvimento com a ICT que } \\
\text { abriga o projeto e a subsidiária } \\
\text { da MNC na definição do } \\
\text { escopo e orçamento, por meio } \\
\text { de sucessivas reuniões } \\
\text { realizadas no ambiente da } \\
\text { ICT. }\end{array}$ & $\begin{array}{l}\text { Capacitação junto ao } \\
\text { pessoal da subsi diaria } \\
\text { na sede da subsidiária } \\
\text { e ou mediante outros } \\
\text { sistemas de } \\
\text { comunicação (vídeo } \\
\text { conferência). }\end{array}$ & \\
\hline & $\begin{array}{l}\text { SMNC } \\
\text { Alfa1 }\end{array}$ & Idem ao da PME. & $\begin{array}{l}\text { Relacionamento entre } \\
\text { equipes de projetos } \\
\text { com outras ICT. }\end{array}$ & \\
\hline
\end{tabular}

Fonte: Resultados da Pesquisa (2013)

$\mathrm{Na}$ fase de execução, o envolvimento em rede permitiu às subsidiárias de MNC um relacionamento maior com outras equipes de projetos, identificando competências em pessoal técnico distribuído em outra região (onde se localizam a ICT e a PME). Para a PME o envolvimento em rede proporcionou a capacitação de seu pessoal junto ao pessoal da subsidiária de MNC (aquisição de capacitação tecnológica), em eventos na sede da subsidiária ou através da utilização de outros sistemas de comunicação (videoconferência).

\subsection{Mecanismos de aprendizagem}

Para melhor análise, os mecanismos de aprendizagem foram divididos em dois grupos: mecanismos de aquisição de conhecimento e mecanismos de conversão de conhecimento. No que diz respeito aos 
mecanismos de aquisição, a subsidiária realizou treinamentos com parte dos técnicos dos projetos, proporcionando ampla troca de conhecimentos (Quadro 5). Essas atividades, que ocorreram com certa frequência ao longo da execução dos projetos, mostraram-se eficazes ao processo de aquisição de conhecimentos. Com relação aos mecanismos de conversão, foram utilizadas estratégias de documentação dos projetos, principalmente nos relatórios parciais e final, além da própria codificação dos softwares desenvolvidos. Outros destaques foram as atividades de socialização, com a utilização de vídeo conferência entre as equipes dos projetos, das subsidiárias e da PME, além da formação de fóruns de discussão sobre problemas técnicos.

Quadro 5: Mecanismos de aprendizagem utilizados por subsidiárias e PME durante os projetos de P\&D.

\begin{tabular}{|c|c|c|c|}
\hline Projetos & Planeja & Execução 2005-2012 & $\begin{array}{l}\text { Apropriação dos } \\
\text { resultados } \\
2011-2012\end{array}$ \\
\hline \multirow[t]{2}{*}{ Projeto 1} & $\begin{array}{l}\text { PME } \\
\text { Beta }\end{array}$ & $\begin{array}{l}\text { Capacitações co mos técnicos da } \\
\text { subsidiária e p articipação em eventos } \\
\text { nacionais e internacionais. }\end{array}$ & $\begin{array}{l}\text { Absorção de } \\
\text { metodologias mais } \\
\text { eficientes de execução } \\
\text { de projeto (m étodo } \\
\text { próprio da subsidiária). }\end{array}$ \\
\hline & $\begin{array}{l}\text { SMNC } \\
\text { Alfa }\end{array}$ & $\begin{array}{l}\text { Partes de seus técnicos participaram de } \\
\text { treinamento conjunto com os } \\
\text { executores do projeto. }\end{array}$ & \\
\hline \multirow[t]{2}{*}{ Projeto 2} & $\begin{array}{l}\text { PME } \\
\text { Alfa1 }\end{array}$ & $\begin{array}{l}\text { Treinamento com técnicos da } \\
\text { subsidiária. Transferência de } \\
\text { conhecimentos entre projetos com } \\
\text { outras ICT. Apoio financeiro a } \\
\text { construção do conhecimento da equipe } \\
\text { em cursos de graduação e pós } \\
\text { graduação }\end{array}$ & $\begin{array}{l}\text { Absorção de } \\
\text { metodologias mais } \\
\text { eficientes de execução } \\
\text { de projeto }(\text { Scrun }) \text {. }\end{array}$ \\
\hline & SMNC & $\begin{array}{l}\text { Parte dos técnicos participou de } \\
\text { treinamento conjunto com os } \\
\text { executores do projeto. }\end{array}$ & \\
\hline
\end{tabular}

Fonte: Resultados da Pesquisa (2013)

No caso da PME, treinamentos técnicos na subsidiária foram utilizados, o que proporcionou a transferência de conhecimentos entre projetos com outras ICT (aquisição externa), bem como o uso de instrumentos de incentivo, como o apoio financeiro para cursos de graduação e pós-graduação aos membros da equipe. Por causa desses treinamentos, outros projetos foram gerados e alguns técnicos desenvolveram ideias de novos projetos, os quais atualmente 
encontram-se documentados em forma de briefings, esperando por novas oportunidades na PME (mecanismo de conversão).

\subsection{Capacidades tecnológicas}

De acordo com o exposto no Quadro 6, tanto as subsidiárias de MNC quanto a PME não obtiveram evolução durante a fase de planejamento do projeto em que participaram. Isso já era esperado, pois se tratam de empresas que atuam na área de projetos há bastante tempo e não estariam propensas a desenvolver novas capacidades partir desse tipo de atividades. Já na fase de execução, as subsidiárias de MNC evoluíram, principalmente na capacidade de gestão distribuída de projetos de inovação. Nesse caso, a subsidiária adicionou a capacidade de gerenciar equipes em diferentes instituições e regiões, identificando complementaridades nas equipes, cuidando para que informações e conhecimentos pudessem circular entre elas e garantindo a convergência de resultados e a escalabilidade dos projetos, reduzindo o risco de vazamento de conhecimentos e de descontinuidade integral das equipes.

Quadro 6: Desenvolvimento de novas capacidades tecnológicas por parte das Subsidiárias e PME durante os projetos de P\&D.

\begin{tabular}{|l|l|l|l|}
\hline Embededness & $\begin{array}{l}\text { Planejamento } \\
\mathbf{2 0 0 4}\end{array}$ & Execução 2005-2012 & $\begin{array}{l}\text { Apropriação dos resultados } \\
\mathbf{2 0 1 1 - 2 0 1 2}\end{array}$ \\
\hline \multirow{2}{*}{ Projeto 1 } & $\begin{array}{l}\text { PME } \\
\text { Beta }\end{array}$ & $\begin{array}{l}\text { Nova metodologia de } \\
\text { acompanhamento e execução de } \\
\text { projeto, com fo co na agilidade dos } \\
\text { processos (m etodologia própria da } \\
\text { subsidiária). }\end{array}$ & $\begin{array}{l}\text { Capacidade de desenvolvimento } \\
\text { de novos produtos e a plicação de } \\
\text { processo mais ágeis pessoal do } \\
\text { projeto des envolvendo novas } \\
\text { propostas). }\end{array}$ \\
\cline { 2 - 5 } & $\begin{array}{l}\text { SMNC } \\
\text { Alfa }\end{array}$ & $\begin{array}{l}\text { Capacidade de gestão distribuída } \\
\text { em projetos de inovação. }\end{array}$ & $\begin{array}{l}\text { Registro de módulos de seu } \\
\text { software de automação comercial } \\
\text { (Middleware). }\end{array}$ \\
\hline Projeto 2 & $\begin{array}{l}\text { PME } \\
\text { Beta }\end{array}$ & $\begin{array}{l}\text { Nova metodologia } \\
\text { acompanhamento e execução de } \\
\text { projeto, com fo co na agilidade dos } \\
\text { processos (Scrum). }\end{array}$ & $\begin{array}{l}\text { Capacidade de desenvolvimento } \\
\text { de novos produtos e a plicação de } \\
\text { processo mais ágeis } \\
\text { projeto desenvolvendo novas do } \\
\text { propostas). }\end{array}$ \\
\cline { 2 - 4 } & $\begin{array}{l}\text { SMNC } \\
\text { Alfa1 }\end{array}$ & $\begin{array}{l}\text { Ampliação da c apacidade de gestão } \\
\text { de P\&D distribuída. }\end{array}$ & $\begin{array}{l}\text { Fornecimento de } \\
\text { controle de medidores para os } \\
\text { clientes (empresas distribuidoras } \\
\text { de energia). }\end{array}$ \\
\hline
\end{tabular}

Fonte: Resultados da Pesquisa (2013) 
A PME também experimentou evolução substancial, pois passou a fazer uso de uma nova metodologia de acompanhamento e execução de projetos, com foco na agilidade dos processos, utilizando-se de uma metodologia própria da subsidiária, transferida via treinamentos comuns e no processo de learning by doing. Além disso, incorporou parte da equipe dos projetos com colaboradores que começaram a elaborar novos projetos de P\&D, alguns com sérias chances de gerar inovações para a PME no setor em que os projetos foram desenvolvidos.

As subsidiárias de MNC, na fase de apropriação de resultados, evoluíram de forma diferenciada. A empresa Alfa, por exemplo, desenvolveu capacidades de oferta flexível de novas disponibilidades em seu software comercial, como parte da solução embarcada em seu produto de hardware, característica visualizada por meio do registro de diversos módulos de seu software de automação comercial (middleware). Já a empresa Alfa1 desenvolveu a capacidade de agregar um novo produto, complementar a seu produto principal (software de controle), baseado em medidores eletrônicos, fato observado a partir da oferta de novos softwares de controle de medidores que Alfa 1 disponibilizou para seus clientes (notadamente, empresas distribuidoras de energia elétrica).

\subsection{Desempenho inovativo}

O Quadro 7 mostra que, a partir de 2009, as subsidiárias de MNC evoluíram com a melhoria do software existente e a implantação de novos módulos, passando, inclusive, a exportá-lo para os países da América Latina. Nesse mesmo período, a PME evoluiu com a criação de novos produtos e ou processos para projetos futuros e com a melhoria de processos já em execução. Isso permitiu uma redução significativa do tempo de entrega de seus produtos, bem como a criação de uma nova metodologia de gestão de projetos que ampliou sua capacidade de planejamento para novos produtos. 
Quadro 7: Desempenho inovativo das subsidiárias e PME a partir de 2009.

\begin{tabular}{|l|l|l|l|}
\hline Projetos & $\begin{array}{l}\text { Planejamento } \\
2004\end{array}$ & Execução 2005-2012 dos & $\begin{array}{l}\text { Apropriação } \\
\text { resultados } \\
\text { 2011-2012 }\end{array}$ \\
\hline \multirow{2}{*}{ Projeto 1 } & $\begin{array}{l}\text { PME } \\
\text { Beta }\end{array}$ & $\begin{array}{l}\text { Novoslayouts de produtos e/ou } \\
\text { processos a serem planejados } \\
\text { e melhoria de processos de } \\
\text { execução. }\end{array}$ & $\begin{array}{l}\text { Redução do tempo de } \\
\text { entrega de produtos. }\end{array}$ \\
\cline { 2 - 5 } & $\begin{array}{l}\text { SMNC } \\
\text { Alfa }\end{array}$ & $\begin{array}{l}\text { Melhoria do software existente } \\
\text { e implantação de novos } \\
\text { módulos. Exportação para } \\
\text { países da América Latina. }\end{array}$ & $\begin{array}{l}\text { Criação de dulos } \\
\text { suplementares due } \\
\text { completam as funções do } \\
\text { módulo principal. }\end{array}$ \\
\hline \multirow{5}{*}{ Projeto 2 } & PME & $\begin{array}{l}\text { Novas metodologias de gestão } \\
\text { de projetos e capacidade } \\
\text { de planejamento de novos } \\
\text { produtos. }\end{array}$ & $\begin{array}{l}\text { Novas metodologias de } \\
\text { gestão de projetos. }\end{array}$ \\
\cline { 2 - 5 } & $\begin{array}{l}\text { SMNC } \\
\text { Alfa1 }\end{array}$ & $\begin{array}{l}\text { Melhoria do software de } \\
\text { acompanhamento fornecido às } \\
\text { distribuidoras de energia. }\end{array}$ & $\begin{array}{l}\text { Criação de novo software de } \\
\text { controle }\end{array}$ \\
\hline
\end{tabular}

Fonte: Resultados da Pesquisa (2013)

Percebe-se, ainda, que os projetos beneficiaram inovativamente as subsidiárias e ambas obtiveram inovação em seus produtos, sendo que o processo na empresa Alfa se deu de forma mais incremental, incluindo importantes modificações em seu produto, tais como: novas funcionalidades; novos componentes tecnológicos em seu algoritmo de software etc. Já no caso da empresa Alfa1, a inovação se deu com o surgimento de um novo produto (software de controle), complementar aos seus medidores. Embora a empresa Alfa1 tenha apresentado uma inovação de produto, ele se enquadra como um produto complementar ao principal, ajudando nas vendas deste.

\subsection{Dinâmica e relação entre os construtos}

Os Quadros 8 e 9 mostram que a PME e as subsidiárias de MNC desenvolveram especificidades de envolvimento diferentes. No caso da PME, o envolvimento cresceu na fase da execução e caiu na fase de apropriação enquanto que nas subsidiárias, na fase de execução, 
o envolvimento permaneceu elevado e a acumulação de capacidades tecnológicas permeou-se de maneira diferenciada, tendo as subsidiárias, inclusive, na última fase do projeto, acumulado capacidades mais substanciais e efetivas, enquanto a PME apresentou capacidades desenvolvidas de efeitos futuros com certo grau de incertezas.

Quadro 8: A evolução dos construtos no tempo da PME.

\begin{tabular}{|l|l|l|l|}
\hline Construtos & Planejamento & Execução & Apropriação \\
\hline $\begin{array}{l}\text { Capacidade } \\
\text { Tecnológica }\end{array}$ & $\begin{array}{l}\text { Não houve } \\
\text { acumulação. }\end{array}$ & $\begin{array}{l}\text { Acumulação de novas } \\
\text { metodologias. }\end{array}$ & $\begin{array}{l}\text { Acumulação de capacidade de } \\
\text { gerar novos projetos. }\end{array}$ \\
\cline { 1 - 3 } & $\begin{array}{l}\text { Sem auton omia e } \\
\text { agindo na } \\
\text { formação da rede } \\
\text { para elaborar o } \\
\text { projeto. }\end{array}$ & $\begin{array}{l}\text { Com autonomia nas decisões de } \\
\text { pessoas; a rede agindo de forma } \\
\text { intensa e os mecanismos de } \\
\text { aprendizagem em uso utilizados } \\
\text { com frequência e eficácia. }\end{array}$ & $\begin{array}{l}\text { Baixa autonomia; menor } \\
\text { relações na rede e menos } \\
\text { mecanismos de aprendizagem. }\end{array}$ \\
$\begin{array}{l}\text { Mecanismo de } \\
\text { Aprendizagem }\end{array}$ & (3 anos) & (4 anos) \\
\hline $\begin{array}{l}\text { Tempo } \\
\text { Acumulado }\end{array}$ & (até 1 ano) & & \\
\hline
\end{tabular}

Fonte: Resultados da Pesquisa (2013)

Quadro 9 - A evolução dos construtos no tempo da subsidiária de MNC.

\begin{tabular}{|c|c|c|c|}
\hline Construtos & Planejamento & Execução & Apropriação \\
\hline $\begin{array}{l}\text { Capacidade } \\
\text { Tecnológica }\end{array}$ & $\begin{array}{l}\text { Não houve } \\
\text { acumulação }\end{array}$ & $\begin{array}{l}\text { Acumulação } \quad \text { de } \\
\text { metodologias. }\end{array}$ & $\begin{array}{l}\text { Acumulação de capacidade de } \\
\text { gerar novos projetos. }\end{array}$ \\
\hline Autonomia & \multirow{3}{*}{$\begin{array}{l}\text { Com autonomia } \\
\text { no } \\
\text { estabelecimento } \\
\text { do escopo dos } \\
\text { projetos } \\
\text { participando da } \\
\text { formação da rede. }\end{array}$} & \multirow{3}{*}{$\begin{array}{l}\text { Com autonomia nas decisões de } \\
\text { pessoas; a rede agindo de forma } \\
\text { intensa e os mecanismos de } \\
\text { aprendizagem em uso utilizados } \\
\text { com frequência e eficácia. }\end{array}$} & \multirow{3}{*}{$\begin{array}{l}\text { Alguma autonomia; maior es } \\
\text { relações na rede e absorção de } \\
\text { novos mecanismos de } \\
\text { aprendizagem. }\end{array}$} \\
\hline Rede & & & \\
\hline $\begin{array}{l}\text { Mecanismo de } \\
\text { Aprendizagem }\end{array}$ & & & \\
\hline $\begin{array}{l}\text { Tempo } \\
\text { Acumulado }\end{array}$ & (até 1 ano) & (3 anos) & (4 anos) \\
\hline
\end{tabular}

Fonte: Resultados da Pesquisa (2013)

Percebe-se que, no caso em estudo, as empresas se beneficiaram das relações de envolvimento (embededdness), contudo, as subsidiárias deverão ter mais velocidade de acumulação de capacidades tecnológicas ao longo do tempo e o processo de coevolução, embora mutuamente benéfico, tende a ser assimétrico. Com efeito, isso já pôde ser apreciado nas fases iniciais do projeto e em sua apropriação, quando se observou que a acumulação de capacidades tecnológicas das subsidiárias produziu resultados mais expressivos, tanto interna como externamente (Quadro 10). 
Quadro 10: Relação entre os construtos da PME e das subsidiárias de MNC

\begin{tabular}{|c|c|c|}
\hline $\begin{array}{l}\text { Resumo dos } \\
\text { construtos }\end{array}$ & PME & SUBSIDIÁRIA \\
\hline $\begin{array}{l}\text { Resultados } \\
\text { Inovativos }\end{array}$ & $\begin{array}{l}\text { - Melhoria de processo. } \\
\text { - Novos projetos. }\end{array}$ & $\begin{array}{l}\text { - Melhoria de produto. } \\
\text { - Novos projetos. } \\
\text { - Abertura de novos mercados } \\
\text { (exterior). }\end{array}$ \\
\hline $\begin{array}{l}\text { Cap. } \\
\text { Tecnológicas }\end{array}$ & $\begin{array}{l}\text { - Metodologia de projeto. } \\
\text { - Capacidade de novos projetos. }\end{array}$ & $\begin{array}{l}\text { - Ampliação da capacidade de } \\
\text { gestão. } \\
\text { - Registro de software. } \\
\text { - Novos produtos. }\end{array}$ \\
\hline Envolvimento & $\begin{array}{l}\text { - Autonomia com pessoal. } \\
\text { - Relação com subsidiária em } \\
\text { rede para treinamento. } \\
\text { - Treinamento, congressos, } \\
\text { fóruns. }\end{array}$ & $\begin{array}{l}\text { - Autonomia no estabelecimento de } \\
\text { escopo dos projetos } \\
\text { - Identificação de novas } \\
\text { competências na rede } \\
\text { - Capacitações, eventos nacionais e } \\
\text { internacionais. } \\
\text { - Absorção de metodologias novas } \\
\text { e eficientes. }\end{array}$ \\
\hline
\end{tabular}

Fonte: Resultado das Pesquisas (2013)

\section{Considerações finais}

A partir deste estudo, pôde-se observar assimetria de autonomia na relação entre subsidiárias e PME (subsidiárias apresentando maior autonomia). Com relação à PME, identificou-se como ponto forte a influência que teve na construção de exigências, competências e habilidades do pessoal selecionado para a execução das atividades do projeto. Contudo, foi constatado que a ausência de mecanismos eficazes de apropriação e transformação de conhecimentos tácitos em explícitos impediu a maximização do aproveitamento do conhecimento gerado. Além disso, como esses grupos foram dissolvidos ao término dos projetos, fica a certeza de que grandes oportunidades deixaram de ser aproveitadas, tanto na operacionalização e melhoria de projetos em andamento, como em projetos futuros.

Quanto ao envolvimento, foi observado que a distância geográfica entre controladora e subsidiária proporcionou o maior envolvimento 
destas com a ICT que abriga o projeto e com a PME. Entretanto, mesmo assim, notou-se que as subsidiárias apresentaram maior tendência em concentrar as decisões da rede, acabando por representar o elo entre os outros participantes da rede (PME e ICT). Consequentemente, pôdese observar que a ICT se relacionou de forma muito mais intensa com a subsidiária na fase de planejamento dos projetos do que com a PME (fase na qual grande parte das decisões era tomada). Já nas demais fases, foi observado maior envolvimento PME no processo, especialmente com a ICT. No fim, foi em função da rede que a PME se beneficiou de capacitações específicas para seu pessoal e as subsidiárias com a viabilidade para o desenvolvimento de outros projetos.

No que diz respeito aos mecanismos de aquisição de conhecimento as subsidiárias se destacaram tanto internamente, com transferência de conhecimento intraequipes, como externamente, com a capacitação de seus recursos humanos em treinamentos, congressos e encontros proporcionados pela rede, sendo alguns deles no exterior. Com relação aos mecanismos de conversão, os destaques foram as atividades de socialização entre equipes das subsidiárias e PME, além da formação de um fórum de discussão sobre problemas técnicos. A PME, por sua vez, se beneficiou da transferência de conhecimentos entre projetos com outras ICT (aquisição externa), tendo como resultado a criação de novos projetos pela equipe, bem como a documentação de possíveis oportunidades futuras de desenvolvimento.

Quanto à evolução das capacidades tecnológicas, as subsidiárias de MNC evoluíram, principalmente em sua capacidade de gestão distribuída de projetos de inovação. Já a PME evoluiu substancialmente, passando a fazer uso de uma nova metodologia de acompanhamento e execução de projetos, com foco na agilidade dos processos, utilizando-se de uma metodologia própria da subsidiária, transferida via treinamentos comuns e no processo de learning by doing. Além disso, a PME incorporou parte da equipe dos projetos como colaboradores que começaram a elaborar novos projetos de P\&D, alguns com grandes chances de gerar inovações para a PME no setor em que os projetos foram desenvolvidos. 
Desse modo, embora se tenha observado assimetria na relação entre subsidiárias de MNC e a PME, o processo de acumulação de capacidades tecnológicas em ambas foi muito positivo, especialmente na apropriação dos resultados por parte das subsidiárias de MNC. Por fim, o estudo demonstra sua contribuição na medida em que fornece direcionadores para que instituições e políticas públicas possam se desenvolver no sentido de equilibrar essa relação, pois, de maneira geral, o desenvolvimento das PME, tanto na melhoria dos mecanismos de apropriação como nos de disseminação de conhecimentos, teria impacto positivo relevante no acúmulo de capacidades dessas empresas e, consequentemente, em seu desempenho inovativo (em sentido estrito), bem como na economia e na geração de empregos (em sentido lato). Ademais, as PME também devem estruturar melhor suas estratégias de participação em redes dessa natureza, estando preparadas para oportunidades de aprendizado, apropriação e desenvolvimento de novos conhecimentos que possam elevar suas capacidades tecnológicas em direção ao desempenho inovativo sustentável, seja pela adoção de práticas positivas nesse sentido, seja pela qualificação e autonomia de suas lideranças.

Este estudo teve como grande limitação a dimensão da rede em estudo, no qual poucos atores e interações entre empresas foram considerados, logo, como sugestão para pesquisas futuras, sugere-se a ampliação dos atores e da rede, inclusive com a tentativa de considerar estudos em que a apropriação dos resultados finais tenha fracassado, empreendendo, dessa forma, um estudo comparativo dos principais fatores envolvidos em cada caso. Outra sugestão seria considerar o estudo em redes TIC em que a autonomia das subsidiárias fosse restrita, seja pela centralização de atividades de P\&D na controladora seja pela centralização das decisões. Esses estudos, que possuem caráter complementar ao aqui debatido, possuem grande potencial de contribuição para o direcionamento de esforços que visem o sucesso da interação em redes no setor, seja pela proposição de novas políticas, seja pela adoção de práticas proativas de gerenciamento e gestão de projetos de inovação. 


\section{Referências}

ALDRICH, Howard. E.; RUEF, Martin. Organizations Evolving, 2. ed. London: SagePublications, 2006, 344p.

ALVES-MAZZOTTI, Alda J. Usos e abusos dos estudos de caso. Cadernos de pesquisa, São Paulo, v. 36, n. 129, p. 637-651, set./dez. 2006.

ANDERSSON, Ulf; FORSGREN, Mats; HOLM, Ulf. The strategic impact of external networks: subsidiary performance and competence development in the multinational corporation. Strategic Management Journal, New Jersey, v. 23, n. 11, p. 979-996, November 2002.

ANDRADE, Rosilene F.; FIGUEIREDO, Paulo N. Dinâmica da acumulação de capacidade tecnológica e inovação em subsidiárias de empresas transnacionais (etns) em economias emergentes: a trajetória da Motorola Brasil. Revista de Administração e Inovação, São Paulo, v. 3, n. 5, p. 73-92, 2008.

ARIFFIN, Norlela; FIGUEIREDO, Paulo N. Internationalization of innovative capabilities: counter-evidence from the electronics industry in Malaysia and Brazil. Oxford development studies, Oxford, v. 32, n. 4, p. 559-583, December 2004.

BAUM, Joel A. C.; SINGH, Jitendra V. Organizationenvironmentcoevolution. In: BAUM, Joel A. C.; SINGH, Jitendra V. (Org.). Evolutionary dynamics of organizations, Oxford: Oxford University Press, 1994, p. 379-402

BELL, Martin; PAVITT, Keith. The development of technological capabilities. In: HAQUE, Irfanul (Org.).Trade, technology andinternational competitiveness. 1st. ed. Washington: The World Bank, 1995. p. 69-101.

BIRKINSHAW, Julian; HOOD, Neil. Multinational subsidiaryevolution: Capabilityand charter change in foreign-owned subsidiary companies. Academyof management review, New York, v. 23, n. 4, p. 773-795, 
October 1998.

BOEHE, Dirk M. Desenvolvimento de produtos em Subsidiárias de empresas multinacionais no Brasil: papéis estratégicos e suas bases organizacionais e econômicas. 2005, 232f. Tese (Doutorado em Administração). - Escola de Administração, Universidade Federal do Rio Grande do Sul, Porto Alegre, 2005.

CÂMARA, Samuel F. Co-evolução: implicações e consequências para as PME's. Fortaleza: UECE, 2012, 27 p.

CANTWELL, John; MUDAMBI, Ram. MNE competence-creating subsidiary mandates. Strategic Management Journal, New Jersey, v. 26, n. 12, p. 1109-1128, October 2005.

CARNEY, Michael; GEDAJLOVIC, Eric. East Asian Financial Systems and the transition from investment-drivento innovation-driven economic development. International Journal of Innovation Management, London, v. 4, n. 03, p. 253-276, September 2000.

CASSIOLATO, José Eduardo; LASTRES, Helena Maria Martins. Sistemas de inovação e desenvolvimento: as implicações de política. São Paulo em perspectiva, São Paulo, v. 19, n. 1, p. 34-45, jan/mar 2005.

CHANG, Yi Ying; MELLAHI, Kamel; WILKINSON, Adrian. Control of subsidiaries of MNCs from emerging economies in developed countries: the case of Taiwanese MNCs in the UK. The International Journal of Human Resource Management, New York, v. 20, n. 1, p. 75-95, January 2009.

FIGUEIREDO, Paulo N.; BRITO, Klauber. The innovation performance of MNE subsidiaries and local embeddedness: evidence from an emerging economy. In: PYKA, Andreas; FONSECA, Maria G. D (Org.). Catching Up, Spill overs and Innovation Networks in a Schumpeterian Perspective. Berlin: Springer Berlin Heidelberg, 2011. p. 171-194 
FIGUEIREDO, Paulo N. Learning, capability accumulation and firms differences: evidence from latecomer steel. Industrial and corporate change, Oxford, v. 12, n. 3, p. 607-643, 2003.

FIGUEIREDO, Paulo N. The role of dual embeddedness in the innovative performance of MNE subsidiaries: evidence from Brazil. Journal of Management Studies, Durham, v. 48, n. 2, p. 417-440, March 2011.

FONSECA, Marcelio S.; FIGUEIREDO, Paulo N. Acumulação de capacidades tecnológicas e aprimoramento de performance operacional: evidências de um estudo de caso em nível de empresa. Revista Brasileira de Inovação, São Paulo. v. 13, n. 2, p. 311-344, jul/dez 2014.

FROHARD, Jaime A. C. Trajetórias de acumulação de capacidades inovadoras, mecanismos de aprendizagem e fatores organizacionais relativos a atividades em gestão de projetos: estudo de caso comparativo inter-empresarial na indústria de bens de capital e de celulose e papel no Brasil. 2009, 276f. Dissertação (Mestrado em Administração) - Escola Brasileira de Administração Pública e de Empresas. Fundação Getúlio Vargas, Rio de Janeiro, 2009.

FROST, Tony S. The geographic sources of foreign subsidiaries' innovations. Strategic Management Journal, New Jersey, v. 22, n. 2, p. 101-123, February 2001.

GARCÍA-MUIÑA, Fernando E.; NAVAS-LÓPEZ, José E. Explaining and measuring success in new business: The effect of technological capabilities on firm results. Technovation, Amsterdam, v. 27, n. 1, p. 30-46, January-February 2007.

GHOSHAL, Sumantra; BARTLETT, Christopher A. Creation, adoption, and diffusion of innovations by subsidiaries of multinational corporations. Journal of International Business Studies, Hants, v. 19, n. 3, p. 365-388, 1988.

GODOY, Arilda Schmidt. A pesquisa qualitativa e sua utilização em administração de empresas. Revista de Administração de Empresas, São Paulo, v. 35, n. 4, p. 65-71, jul./ago. 1995. 
GRONUM, Sarel; VERREYNNE, Martie-Louise; KASTELLE, Tim. The Role of Networks in Small and Medium-Sized Enterprise Innovation and Firm Performance. Journal of Small Business Management, New Jersey, v. 50, n. 2, p. 257-282, March 2012.

HEDLUND, Gunnar. The hypermodern MNC- a heterarchy?. Human resource management, New Jersey, v. 25, n. 1, p. 9-35, 1986.

KIM, Linsu. Building technological capability for industrialization: analytical frameworks and Korea's experience. Industrial andcorporate change, Oxford, v. 8, n. 1, p. 111-136, 1999.

KOKKO, Ari; KRAVTSOVA, Victoria. Innovative capability in MNC subsidiaries: evidence from four European transition economies. PostCommunist Economies, New Jersey, v. 20, n. 1, p. 57-75, March 2008.

LALL, Sanjaya. Technological capabilities and industrialization. World Development, Amsterdam, v. 20, n. 2, p. 165-186, fev. 1992

LAMAS, Zainab J.; GODOI, Christiane K.; FEUERSCHUTTE, Simone G. A perspectiva co-evolutiva como lógica de análise das formas organizacionais. In: Encontro da Associação Nacional de Pós-Graduação e Pesquisa em Administração, XXIX, 2005, Brasília. Anais... Brasília: EnANPAD, 2005, p. 1-16.

LASAGNI, Andrea. How can external relationships enhance innovation in SMEs? New evidence for Europe. Journal of Small Business Management, New Jersey, v. 50, n. 2, p. 310-339, April 2012.

LEWIN, Arie Y.; LONG, Chris P.; CARROLL, Timothy N. The coevolutionof new organizational forms. Organization Science, Dallas, v. 10, n. 5, p. 535-550, October 1999.

LI, Dan.; FERREIRA, Manuel P.; SERRA, Fernando R.. Technology transfer within MNEs: Inter-subsidiary competition and cooperation, Revista de Administração e Inovação, São Paulo, v. 6, n. 1, p. 139158, 2009.

LIU, Ju; CHAMINADE, Cristina. Dynamics of a technological innovator network and its impact on technological performance. Innovation, New Jersey, v. 12, n. 1, p. 53-74, 2010. 
LIU, Xuefeng; WU, Xiaobo. Technology embeddedness, innovation differentiation strategies and firm performance: Evidence from Chinese manufacturing firms. Innovation, New Jersey, v. 13, n. 1, p. 20-35, April 2011.

LÜTZ, Sussane. Learning through intermediaries: the case of interfirm research collaboration. In: EBERS, Mark (Org.). The Formation of InterOrganizational Networks, Oxford: Oxford University Press, 1997.p. 220-237.

MALERBA, Franco; ORSENIGO, Luigi. Schumpeterian patterns of innovation. Cambridge Journal of Economics, Oxford, v. 19, n. 1, p. 47-65, February 1995.

MCKELVEY, Bill. Perspective-quasi-natural organization science. Organization Science, Dallas, v. 8, n. 4, p. 351-380, August 1997.

MEYER, Klaus E.; MUDAMBI, Ram; NARULA, Rajneesh. Multinational enterprises and local contexts: the opportunities and challenges of multiple embeddedness. Journal of Management Studies, Durham, v. 48, n. 2, p. 235-252, March 2011.

MILES, Matthew B.; HUBERMANA. Michael. Qualitative Data Analysis: an expanded sourcebook. 2. ed. London: Sage Publications, 1994. 339 p.

NELSON, Richard R. Coevolution of industry structure, technology and supporting institutions, and the making of comparative advantage. International Journal of the Economics of Business, New Jersey, v. 2, n. 2, p. 171-184, 1995.

NONAKA, Ikujiro; TAKEUCHI, Hirotaka. Gestão do conhecimento. Tradução Ana Thorell. Porto Alegre: Bookman, 2008.

POWELL, Walter W.; KOPUT, Kenneth W.; SMITH-DOERR, Laurel. Interorganizational collaboration and the locus of innovation: Networks of learning in biotechnology. Administrative Science Quarterly, New York, v. 41, n. 1, p. 116-145, March 1996. 
RUAS, Roberto; ANTONELLO, Claudia S.; BOFF, Luiz H.. Os novos horizontes de gestão: aprendizagem organizacional e competências. São Paulo: Bookman, 2005.

SALLES FILHO, Sérgio et al. Avaliação de impactos da Lei de Informática: uma análise da política industrial e de incentivo à inovação no setor de TICs brasileiro. Revista Brasileira de Inovação, São Paulo, v. 11, p. 191-218, jul. 2012.

STALLIVIERI, Fabio; MATOS, Marcelo; SOUZA, Gustavo J. G.. Influência dos processos interativos no desempenho inovativo de empresas inseridas em aglomerações produtivas intensivas em conhecimento. Textos para Discussão 205, Universidade Federal Fluminense, Rio de Janeiro, Out., 2006.

VAALER, Paul M. How do MNCs vote in developing country elections? Academy of Management Journal, New York, v. 51, n. 1, p. 21-43, February, 2008.

VON ZEDTWITZ, Maximilian et al. Managing foreign R\&D in China. Research-Technology Management, Vancouver, v. 50, n. 3, p. 19-27, 2007.

YIN, Robert K. Estudo de caso - planejamento e métodos. 2. ed. Porto Alegre: Bookman, 2001.

Artigo recebido em: 4/9/2014

Aprovado em: 25/11/2014 